\title{
Attitudes of general practitioners and midwives towards ethnicity-based haemoglobinopathy- carrier screening
}

\author{
Suze MPJ Jans ${ }^{\star, 1,3}$, Ank de Jonge ${ }^{2}$, Lidewij Henneman ${ }^{1,4}$, Martina C Cornel $^{1}$ and \\ Antoinette LM Lagro-Janssen ${ }^{3}$
}

Haemoglobinopathies (HbP) are severe autosomal recessive disorders with high prevalence among certain ethnic groups. World Health Organisation (WHO) advises implementing screening programmes for risk groups. Research in the Netherlands has shown that general practitioners and midwives do not perceive ethnicity as a risk factor for HbP. Moreover, registration of ethnicity is a controversial societal issue, which may complicate the introduction of a national preconception or antenatal carrier screening programme. This study investigates attitudes, intention and behaviour of general practitioners and midwives towards ethnicity-based HbP-carrier screening in general. A structured questionnaire based on the Theory of Planned Behaviour was sent by mail to a random selection of $\mathbf{2 1 0 0}$ general practitioners and $\mathbf{1 8 0 0}$ primary care midwives. Response was $35 \%$ (midwives $44.2 \%$; GPs $27.6 \%$ ). Although $45 \%$ of respondents thought that offering a carrier test on the basis of ethnicity alone should become national policy, it is currently not carried out. The main factor explaining lack of intention towards ethnicity-based HbP-carrier screening was subjective norm, the perception that their peers do not think they should offer screening (52.2\% variance explained). If ethnicity-based $\mathrm{HbP}$-carrier screening would become national policy, most professionals report that they would carry this out. Most respondents favoured ethnicity registration for health purposes. As most practitioners look for role models among peers, debate among general practitioners and midwives should be encouraged when new policy is to be developed, articulating the voices of colleagues who already actively offer HbP-carrier screening. Moreover, primary care professionals and professional organisations need support of policy at national level. European Journal of Human Genetics (2012) 20, 1112-1117; doi:10.1038/ejhg.2012.72; published online 2 May 2012

Keywords: haemoglobinopathies; ethnicity; carrier screening; primary care; attitude; Theory of Planned Behaviour

\section{INTRODUCTION}

Haemoglobinopathies (HbP) such as sickle cell disease (SCD) and thalassaemia are autosomal recessive disorders with severe anaemia, variable but life-long morbidity and currently with a shortened lifespan due to multi-organ ischaemic damage. ${ }^{1-3}$ Couples in which both partners are carriers of $\mathrm{HbP}$ have an one-in-four chance in each pregnancy of giving birth to an affected child. HbP is one of the world's main genetic disorders but occur more frequently in current or formerly malaria-endemic areas, such as Africa, the Mediterranean region, the Middle East and South-East Asia. Owing to immigration, these disorders are now also common in non-endemic countries ${ }^{3}$ with an estimated prevalence ranging from 5 to $40 \%$ depending on ancestry. ${ }^{4}$ The prevalence of a positive carrier status of $\mathrm{HbP}$ in the Netherlands has been estimated at $4-14 \%$ depending on ethnic background ${ }^{5}$ with a birth prevalence of severe $\mathrm{HbP}$ of about 60 infants among 182000 total births. ${ }^{6}$

In 2006, the World Health Organisation (WHO) urged member states to increase the awareness of SCD and to develop services that integrate carrier detection and genetic counselling within existing primary healthcare systems, in addition to the services of specialists such as clinical geneticists and paediatricians. ${ }^{4,7}$ Such genetic population screening programmes have several social, ethical and technological issues, which may vary according to the type of screening. Universal neonatal screening as offered in the public health setting generally serves the purpose of timely detection of a disorder to prevent further illness. Ethical concerns centre primarily on objections to abortion, embryo selection, and concerns on eugenics and medicalisation of care, and are especially relevant in the context of prenatal and preconceptional genetic screening, where prevention is not the primary purpose. In the preconceptional or prenatal setting, the primary aim of any genetic disorderrelated screening programme is a reproductive choice. ${ }^{8}$ Although preconception carrier screening provides prospective parents with the most reproductive choice, antenatal carrier screening has practical advantages: it reaches the target population more easily. This article is limited to preconception and antenatal HbP-carrier screening. Although (ethnic) diversity and heterogeneous distribution of $\mathrm{HbP}$ may make the introduction of such a programme challenging, it is currently thought to be possible to develop an appropriate programme that meets the ethical considerations for the introduction of genetic screening programmes as agreed upon at European level. ${ }^{9}$

${ }^{1}$ Department of Clinical Genetics, Section of Community Genetics, EMGO Institute for Health and Care Research, VU University Medical Center, Amsterdam, The Netherlands; ${ }^{2}$ Department of Midwifery Science, EMGO Institute for Health and Care Research, VU University Medical Center, Amsterdam, The Netherlands; ${ }^{3}$ Department of Primary Care and Community Care, Women's Studies Medicine, Radboud University Medical Center, Nijmegen, The Netherlands; ${ }^{4}$ Department of Public and Occupational Health, EMGO Institute for Health and Care Research, VU University Medical Center, Amsterdam, The Netherlands

${ }^{*}$ Correspondence: SMPJ Jans, Department of Clinical Genetics, Section of Community Genetics, EMGO Institute for Health and Care Research, VU University Medical Center, BS7, D423, PO Box 7057, 1007 MB, Amsterdam, The Netherlands. Tel: +31 20 4446446; Fax: +31 20 4448181; E-mail: s.jans@vumc.nl

Received 7 September 2011; revised 14 March 2012; accepted 15 March 2012; published online 2 May 2012 
England is an example of a country where a linked antenatal carrier screening (both targeted and universal, depending on prevalence) and neonatal screening programme (universal) for $\mathrm{HbP}$ is available. ${ }^{10}$ This policy is supported by the National Institute for Health and Clinical Excellence (NICE), which recommends (preconception) counselling and carrier testing. ${ }^{11}$ Carriers can be identified by a simple and inexpensive blood test (Hb-electrophoresis or high performance liquid chromatography (HPLC)), allowing couples preferably before pregnancy to be informed about their risk, giving them a wider scope of reproductive options.

Although universal carrier screening, in which all women regardless of their ethnicity who are either pregnant or planning to become pregnant are offered carrier screening, may be preferable in equitable terms, this may not always be preferred in economic terms because in some geographical areas prevalence may be too low to warrant universal screening even though this means some cases may be missed. ${ }^{12}$ Even if universal screening would be the goal, women should always be offered the choice to opt out. Information on risk based on her ethnic background can be used to support women, making an informed choice about whether to accept screening or not. For example, targeted ethnicity-based screening as advised by the American College of Obstetricians and Gynecologists (ACOG) may be more appropriate. ${ }^{13}$ This requires health professionals, such as GPs and midwives, to identify couples at risk by taking an ethnicity-related history by asking them about their ancestry in conjunction with offering them information about HbP-carrier screening when women (and their partners) enter into care. Initiatives have been undertaken to develop instruments to help decide who is eligible for testing and who is not. ${ }^{10,14,15}$ Although implemented in England, this still awaits further discussion in the Netherlands.

Pregnant women are mostly cared for in primary care by midwives and occasionally by GPs and are currently at best offered carrier testing on the basis of anaemia, a positive family history or at the personal discretion of midwives and GPs in the Netherlands. ${ }^{16-18}$ However, if (primary) healthcare services want to adequately meet the needs of the whole population, health professionals should be aware of the specific healthcare requirements of certain ethnic groups.

In the past and even still today, ancestry or ethnicity-based HbP screening has not been without controversy. ${ }^{19-21}$ A recent study showed ethnic registration to be a controversial issue in the Netherlands because of its relationship with the Second World War and lingering feelings of guilt in Dutch society, causing it to be a barrier for the introduction of HbP-carrier screening. ${ }^{22}$ Moreover, in a pilot study, primary care professionals expressed that although they support $\mathrm{HbP}$-carrier screening, they do not interpret ethnicity as a risk marker for HbP. ${ }^{23}$ In order to offer equitable health services to all groups in society, health professionals need to be aware of ethnicityrelated health needs without the fear of raising issues of discrimination or stigmatisation. As attitudes of health professionals may influence clinical practice, the specific attitudes of such professionals towards ethnic registration are of interest.

The aim of this study was to investigate the attitude, intention and behaviour of midwives and GPs towards ethnic registration and their willingness to undertake carrier testing for clients and patients on the basis of ethnicity.

\section{MATERIALS AND METHODS}

\section{Questionnaire}

A cross sectional study was designed by means of a structured questionnaire based on a previous pilot study ${ }^{23}$ including direct measures of the main constructs of the Theory of Planned Behaviour (TPB; Figure 1). TPB interprets

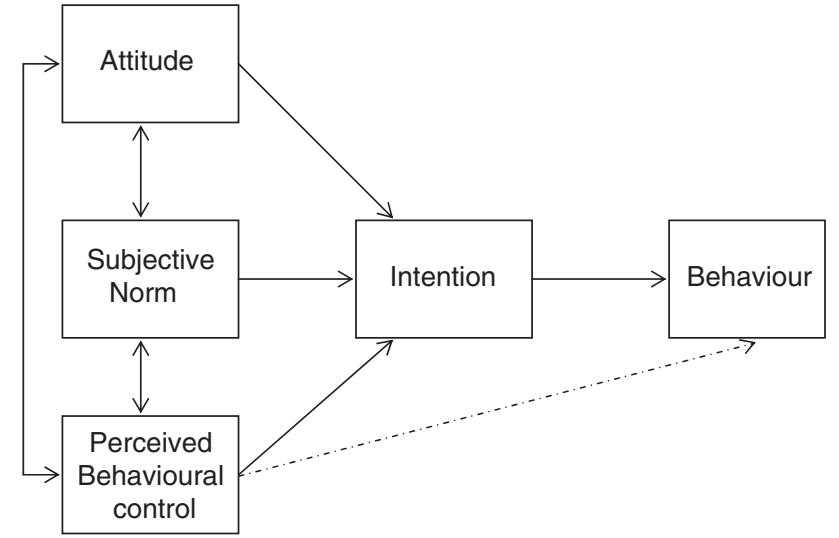

Figure 1 Theory of Planned Behaviour. ${ }^{23}$

the behavioural intentions concerning performance as the most immediate and important predictor of whether people perform a certain behaviour. ${ }^{24}$ The behaviour of interest in this study was offering patients a HbP-carrier test on the basis of their ethnicity, which was explained to participants in the introduction to the questionnaire. We underlined the fact that the amount of patients at risk in their practice and whether or not they tested them for (carrier status of) $\mathrm{HbP}$ at present was irrelevant to being able to answer the questions.

The relationship between attitudes, subjective norm and perceived behavioural control is described by the theory as the underlying foundational belief about the intention of performing the behaviour.

Attitude was measured by using multiple word pairs to answer two questions. First, what do you think about offering your patients a carrier test for HbP solely on the basis of ethnicity (regardless of family history)? A sum-score was then calculated from answers scored on a 7-point scale using the following word pairs: bad-good, nonsense-important, tough-easy, undesirabledesirable, harmful-beneficial and discriminating-privilege. The results showed good consistency for the total score (Cronbach's alpha 0.86). The one factor model fitted well using exploratory factor analysis, all items loaded onto one factor.

Second, what do you think about registering the ethnicity of your patients? A sum-score was calculated from answers scored on a 7-point scale using the following word pairs: wrong-good, harmful-beneficial, nonsense-appropriate, awkward-useful, discriminating-harmless and objectionable-desirable. (Cronbach's alpha 0.89). All items were loaded on one factor using exploratory factor analysis.

Subsequent questions were answered with single word pairs. The question, Do you think your colleagues believe a carrier test solely on the basis of ethnicity should be offered to patients (certainly not (1)-certainly (7))? measured the subjective norm of the professional groups. Behavioural control was measured with the following question: Are you currently able to offer your patients a carrier test for HbP on the basis of ethnicity alone (certainly not (1) -certainly (7))?

Two questions measured intention: Do you intend to offer your patients a carrier test for HbP exclusively on the basis of ethnicity in the future (certainly not (1) -certainly (7))? and Do you intend to offer your patients a HbP-carrier test solely on the basis of ethnicity, should this become a national policy (certainly not (1)-certainly (7))?

Behaviour was measured by asking the following questions: Do you at present offer your patients a HbP-carrier test solely on the basis of ethnicity (never (1)-always (7))? and Do you offer your patients with unresolved anaemia and no familial history a HbP-carrier test (never (1)-always (7))?

Responders were also asked if they thought that: A HbP-carrier test on the basis of ethnicity alone should become national policy (binary answer: yes (1) or no (2)). Finally, they were asked some basic characteristics (location of practice, estimated percentage of population from the group at risk in their practice and work experience). 
The final version of the questionnaire was approved by members of an expert group that consisted of members of the GP and midwifery professions, a representative from the national patient organisation and researchers in the field of $\mathrm{HbP}$.

\section{Respondents}

The questionnaire was accompanied by a letter of introduction explaining the aim of the project, that is, exploring the opinion of health care professionals about offering patients a HbP-carrier test on the basis of their ethnicity and underlining the fact that no specific knowledge about $\mathrm{HbP}$ was necessary to be able to answer the questions. This was sent by post to 2100 GPs and 1800 primary care midwives between November and December 2009. GPs were randomly selected from the total population of GPs (roughly 8000) by the Netherlands Institute of Health Services Research (NIVEL). The total number of midwives is small in the Netherlands; therefore, all primary care midwives were sent a questionnaire. No reminders were sent out and no incentives were offered to participate in the study.

\section{Analysis}

Differences between GPs and midwives were assessed by a two-tailed $t$-test and $\chi^{2}: P$-values $<0.05$ are reported as statistically significant. Direct measures of the main constructs of the TPB (attitude, subjective norm, perceived behavioural control and intention) are reported as a mean. Standard linear regression analysis was applied analysing data obtained according to the TPB in order to explain the behaviour of midwives and GPs towards ethnicity-based HbP-carrier testing (Figure 1). Variables were added backwards. Two tailed values for Pearson's correlations are reported between determinants from the TPB. All data were analysed in SPSS 15.01 for Windows (SPSS Inc., Chicago, IL, USA).

\section{RESULTS}

The questionnaire was returned by 1346 primary health care workers: 795 midwives (response rate 44.2\%) and 551 GPs (response rate $27.6 \%$ ) resulting in a total response rate of $35 \%$.

Respondent characteristics are presented in Table 1. About half of the respondents worked in urban areas. The average working experience was 14 years. More midwives came from urban areas compared to the GPs and they had a significantly longer working experience. The estimated percentage of patients from ethnic minorities in the practices showed a wide distribution of $0-95 \%$ with a mean of $16.6 \%$ (SD 18.7\%). The midwives reported significantly higher estimates of clients from the groups at risk for $\mathrm{HbP}$ in their practices.

Results according to items of the TPB are shown in Table 2.

\section{Attitude}

On average primary care providers have a fairly positive attitude towards offering a test solely on the basis of ethnicity and regardless of family history, midwives being more positive than GPs. The midwives also displayed a more positive attitude towards the registration of ethnicity.

Table 1 Characteristics of respondents

\begin{tabular}{|c|c|c|}
\hline & GPS, $N=551$ & Midwives, $\mathrm{N}=795$ \\
\hline Urban location of practice, $n(\%)^{a}$ & $255(46.4)^{c}$ & $452(56.9)$ \\
\hline $\begin{array}{l}\text { Estimated average percentage of patients } \\
\text { from population at risk in practice }{ }^{a}\end{array}$ & $12.9^{\mathrm{c}}$ & 19.1 \\
\hline Years of experience $(\text { mean } \pm S D)^{b}$ & $11.3(9.0)^{\mathrm{c}}$ & $17.3(9.3)$ \\
\hline
\end{tabular}

\section{Subjective norm}

Both GPs and midwives were less positive about what they thought their colleagues opinions were towards testing on the basis of ethnicity. Most of them thought their colleagues would not recommend screening based on ethnicity.

\section{Perceived behavioural control}

Although in practice the laboratory test is easily available, the responses were close to the scale average. GPs felt somewhat more able to actually carry out a HbP-carrier test compared with midwives.

\section{Intention}

GPs scored the intention of offering a HbP-carrier test to their patients on the basis of ethnicity alone, more negative compared with midwives, who scored almost neutral. However, if this were to become national policy, most participants did express the intention to offer this to their patients: midwives significantly more so than GPs.

\section{Current test behaviour}

The scores for the questions on current behaviour showed that both GPs and midwives almost never offer a carrier test for $\mathrm{HbP}$ on the basis of ethnicity alone (mean scores 1.9 and 1.8). On the other hand, specifically midwives were prepared to test patients on the basis of unexplained anaemia as instructed by the guidelines of their professional organisations (mean score 5.2). GPs, however, were less inclined to do so (mean score 4.2 ); the difference was significant.

Of all primary care providers, $45 \%$ thought that offering a test for carrier status on the basis of ethnicity alone should become national policy, GPs thought so significantly less often than midwives.

\section{Explaining intention and behaviour}

For both midwives and GPs together, the intention of offering patients a HbP-carrier test on the basis of ethnicity alone was largely explained by three factors: the attitude towards offering patients a carrier test for $\mathrm{HbP}$ only on the basis of ethnicity, subjective norm and control over the ability to effectuate the test. This model explained $52.2 \%$ of the variance $(P<0.001)$. The subjective norm, that is, what GPs and midwives perceived their colleagues' opinion to be, contributed most to the model $(\beta=0.49 P<0.001)$.

Variance changed only slightly by adding attitude towards the registration of ethnicity to the model (explained variance $52.5 \%$ $P<0.001)$. In this model, attitude towards the registration of ethnicity

Table 2 Constructs of TPB, comparison between GPs and midwives

\begin{tabular}{lcc}
\hline & GPs mean & Midwives mean \\
& score (SD) & score (SD) \\
\hline Attitude towards testing on the basis of ethnicity & $4.6^{\mathrm{a}}(1.3)$ & $4.9(1.3)$ \\
Attitude towards the registration of ethnicity & $4.5^{\mathrm{a}}(1.4)$ & $5.6(1.2)$ \\
in daily practice & & \\
Subjective norm & $3.6(1.4)$ & $3.8(1.7)$ \\
Perceived behavioural control & $4.4^{\mathrm{a}}(2.1)$ & $4.0(2.1)$ \\
Intention on the basis of ethnicity & $3.4^{\mathrm{a}}(1.7)$ & $3.9(1.7)$ \\
Intention on the basis of national policy & $5.1^{\mathrm{a}}(1.8)$ & $5.7(1.7)$ \\
Current behaviour & $1.9(1.4)$ & $1.8(1.6)$ \\
Current behaviour on basis of guidelines & $4.2^{\mathrm{a}}(2.1)$ & $5.2(2.1)$ \\
\hline Abbreviation: GP, general practitioner; TBP, Theory of planned behaviour. ${ }^{a}$-test, two tailed \\
significant $P<0.001$.
\end{tabular}


was the second most important contributor $(\beta=0.31 \quad P<0.001)$. Characteristics of the participants, such as percentage of population from the group at risk in their practice, work experience and location of practice, did not influence intention towards screening for carrier status of $\mathrm{HbP}$ on the basis of ethnicity.

\section{DISCUSSION}

Although at present midwives and GPs in the Netherlands do not carry out HbP-carrier testing solely on the basis of their patient's ethnic background, they generally have a positive attitude towards ethnicity-based carrier screening. This finding is supported by the results of other studies. ${ }^{23,25}$ According to the TPB, subjective norm influences intention and behaviour. As health care professionals apparently only have very few examples of colleagues who carry out this type of testing, they are not inclined to do so in their own practice environment. However, they are prepared to follow guidance should carrier screening become national policy. Control over the ability to administer the test was also part of the model that explained intention and behaviour. Midwives especially seemed less than secure in their capability of carrying out a test for HbP-carrier status as they scored significantly lower on this item (personal control) when compared to GPs. Although ordering a HbP-carrier test is relatively simple, the interpretation of the results is not always straight forward. This requires more knowledge than health professionals may have ${ }^{26,27}$ and may explain why health professionals are reluctant in offering carrier testing for HbP. Another reason may be that health professionals incorrectly believe they are legally restricted to offer carrier screening because of the Dutch Population Act. ${ }^{28}$

Interestingly, the attitude of midwives towards the registration of ethnicity in daily practice was much more positive when compared with GPs. One explanation may be that midwives are already used to registering the ethnicity of their clients and in contrast to GPs also have the possibility to do so in the software they use. It is unclear in which manner midwives (and GPs) determine ethnicity; if and what questions are asked or whether this is self reported or otherwise determined. This important and interesting point needs further investigation in the future.

As we wanted to know what health professionals thought in general about ethnicity-related HbP screening, we did not specify when the screening should take place; either preconceptionally or antenatally. It is not inconceivable that attitudes may differ between the two as reproductive options during the antenatal period are limited for a carrier couple. The questionnaire was used in a previous pilot project $^{23}$ and discussed in the expert group. Despite this the question A HbP-carrier test on the basis of ethnicity alone should become national policy could be interpreted in several ways and is therefore one of the limitations of the study. It is difficult to attribute definitive meanings to the answers with this question: A person who answers 'no' might do so either because he/she believes that screening should only be offered if universal or because they do not believe such screening for HbP should be offered at all in the Netherlands or that it should be an individual decision at professional level. This needs further study.

Although the response rate was low in this study (35\%); it was reached without sending out reminders and the response rate among GPs was much lower resulting in a lower overall response rate. We expected to receive more questionnaires from those GPs and midwives practicing in urban areas with a higher percentage of the population at risk. This was not the case, especially in the group of GPs. The spread of practice location, however, corresponds with national spread of GPs, indicating a representative sample. ${ }^{29}$
Responding GPs estimated only slightly more patients from ethnic minorities in their practice (12.9\%) compared with the national population (11.2\% non-western). In 2008, $19.6 \%$ of women in Dutch midwifery practices were of non-Dutch ethnicity, which is comparable to what the midwives in the study estimated. ${ }^{30}$ Other surveys have encountered similar problems in terms of response and indicated that a high workload prevented health professionals from participating. ${ }^{31}$ A lack of interest or failure to see the importance of the subject and the popularity of GPs as research objects may also have influenced the lack of enthusiasm among GPs in returning the questionnaire. Although the response rate was low, there was no evidence of selection bias.

Achterberg et $a l^{32}$ argued that effective implementation of screening for $\mathrm{HbP}$ will require changes at both regime (suppliers and users) and landscape level (institutions, material social, political and legal infrastructure), but that such change is difficult to achieve without an active orchestrating role of the government. This contradicts present governmental policy that expects the field of health professionals to initiate such policies. The fact that similar programmes in the Netherlands have been initiated by the government in the past ${ }^{33}$ makes this all the more curious. Whether or not to test for (carrier status of) $\mathrm{HbP}$ during reproductive life (ie, preconceptional, antenatal or neonatal) has been debated since the seventies and eighties. Possibly, previous sensitivities surrounding ethnicity and ethnic registration are still applicable today. ${ }^{22}$

As most women in the Netherlands are cared for by midwives when pregnant $^{30}$ and most women will probably meet with their GP at some point during their reproductive life, they would be the professionals of choice to offer HbP-carrier screening to women and/or couples.

Morgan et $a l^{34}$ showed that fewer than $28 \%$ of gynaecologists offered their pregnant patients screening for cystic fibrosis, on the basis of all of the criteria in the guidelines of the ACOG. One explanation given was that almost $60 \%$ did not feel familiar enough with genetics to offer screening. ${ }^{35}$ This lack of knowledge displays a need for continuing education in genetics, a problem which probably also exists among primary healthcare professionals. Vansenne et a ${ }^{26}$ reported a lack of $\mathrm{HbP}$ knowledge and clinical experience influencing primary care practitioners' behaviour in neonatal screening, which confirms the need for further education.

Besides knowledge development, the use of specific antenatal laboratory forms (such as used for the Antenatal Screening Programme for Infectious Diseases and Pregnancy Immunisation, PSIE, programme ${ }^{36}$ ) could prompt health professionals to initiate $\mathrm{HbP}$-carrier testing and may encourage implementation of testing. As the design of this form is not the responsibility of professional organisations, such as those of GPs and midwives, it would still require some form of governmental or laboratory experts' initiative.

It has been shown that informed choice is less well facilitated for women from different ethnic backgrounds in other areas of antenatal screening, ${ }^{37}$ although several researchers have shown that both preconception and antenatal screening is acceptable among the population at risk. ${ }^{38-40}$ Ethnic diversity poses an extra challenge to health care professionals to deliver equitable services. ${ }^{41}$ The discussion in the Netherlands has focused primarily on equality in health care and concerns over stigmatisation of certain groups in society; however, the realisation that this may limit health care equity for some has only surfaced in recent years. ${ }^{22}$ If we want to strive to provide equitable healthcare services for all, it is important that health professionals such as midwives and GPs are aware of these issues and that discussions on equity, equality and access are part of (continuing) 
education programmes to enable them to provide women with the care they need. Introduction of HbP-carrier screening should be a part of meeting these needs, as proposed by the WHO.

Many countries have been hesitant about introducing ethnicitybased HbP-carrier screening based on negative reports related to discrimination and stigmatisation of groups at risk. In the past SCD has been wrongly addressed as a 'black disease' and care for these patients has been and very often still is shadowed by mistrust and health care discrimination. ${ }^{19,42}$ Associating (carrier status of) $\mathrm{HbP}$ with particular ethnic groups may undermine the success of a possible screening programme. For such a programme to be effective, equitable facilities for diagnosis and treatment should be available. ${ }^{43}$ Moreover, the correct determination of ethnicity is important, but it could also be possible that health professionals and/or their patients find this difficult; they may need to be supported by a tool to determine risk or universal screening should be considered. ${ }^{15,44}$

We conclude that most practitioners are willing to offer screening solely on the basis that ethnicity should become national policy, however, not all. The fact that not all midwives and GPs answered that they are not prepared to implement a national guideline for $\mathrm{HbP}$-carrier screening is unusual. The background of this result and a more in depth analysis of the possible barriers for ethnicity-based $\mathrm{HbP}$-carrier screening warrant further investigation.

In developing and implementing new policy with regard to HbP-carrier screening, debate among GPs and midwives should be encouraged, articulating the voices of colleagues who already actively offer HbP-carrier screening. Opinion leaders and professional organisations of primary health care professionals should be supported by policy at national level when targeting GPs and midwives to implement HbP-carrier screening.

\section{CONFLICT OF INTEREST}

The authors declare no conflict of interest.

\section{ACKNOWLEDGEMENTS}

We wish to thank all the midwives and GPs who participated in the study, Steve Abbott for his editing and proofreading, and Anne Marie Plass for supervising the start of the study. This article is the result of a research project of the Centre for Society and Genomics in the Netherlands, funded by the Netherlands Genomics Initiative.

\section{ETHICAL APPROVAL}

The study protocol was approved by the Medical Ethics Committee of the VU University Medical Centre in Amsterdam.

1 Dauphin-McKenzie N, Gilles JM, Jacques E, Harrington T.: Sickle cell anaemia in the female patient. Obstet Gynecol Surv 2006; 61: 343-352.

2 Platt OS, Brambilla DJ, Rosse WF et al: Mortality in sickle cell disease. Life expectancy and risk factors for early death. N Engl J Med 1994; 330: 1639-1644.

3 Weatherall DJ, Clegg JB: Inherited haemoglobin disorders: an increasing global health problem. Bull World Health Organ 2001; 79: 704-712.

4 Modell B, Darlison M: Global epidemiology of haemoglobin disorders and derived service indicators. Bull World Health Organ 2008; 86: 480-487.

5 Giordano PC, Harteveld CL: Prevention of hereditary haemoglobinopathies in the Netherlands. Ned Tijdschr Geneeskd 2006; 150: 2137-2141.

6 Peters M, Fijnvandraat K, van dT X et al: One-third of the new paediatric patients with sickle cell disease in the Netherlands are immigrants and do not benefit from neonatal screening. Arch Dis Child 2010; 95: 822-825

7 World Health Organisation: Sickle Cell Anaemia, the 59th World Health Assembly; 117th Session 2006 Agenda item 4.8; Resolution EB117.R3.

8 De Wert GM, Dondorp WJ, Knoppers BM: Preconception care and genetic risk: ethical issues. J Community Genet 2011; e-pub ahead of print 29 December 2011.
9 Population genetic screening programmes: technical, social and ethical issues Eur J Hum Genet 2003; Suppl 2: S5-S7.

10 National Health Service: Sickle Cell \& Thalassaemia Screening Programme 2011. Available from: http://sct.screening.nhs.uk (accessed on 16 August 2011).

11 National Collaborating Centre for Women's and Children's Health. Antenatal care. Routine Care for the Healthy Pregnant Woman. London: National Institute for Health and Clinical Excellence 2010 Report no: CG62.

12 Hinton CF, Grant AM, Grosse SD: Ethical implications and practical considerations of ethnically targeted screening for genetic disorders: the case of hemoglobinopathy screening. Ethn Health 2011; 16: 377-388.

13 American College of Obstetricians and Gynecologists: Practice Bulletin no. 78 hemoglobinopathies in pregnancy. Obstet Gynecol 2007; 109: 229-237.

14 Lakeman P, Henneman L, Bezemer PD, Cornel MC, ten Kate LP.: Developing and optimizing a decisional instrument using self-reported ancestry for carrier screening in a multi-ethnic society. Genet Med 2006; 8: 502-509.

15 Dyson SM, Culley L, Gill C et al: Ethnicity questions and antenatal screening for sickle cell/thalassaemia [EQUANS] in England: a randomised controlled trial of two questionnaires. Ethn Health 2006; 11: 169-189.

16 Jans S, Beentjes M: Anaemia in Midwifery Practice, Guideline. Utrecht: KNOV, 2010.

17 Nederlands Huisartsen genootschap: Preconception Care, M97. Utrecht: NHG 2011.

18 Wijk MAM, Mel M, Muller PA et al: Anaemia, Guideline, M76. Utrecht: NHG, 2003.

19 Anionwu EN, Atkin K: The Politics of Sickle Cell and Thalassaemia. Buckingham Open University Press, 2001.

20 Dyson SM: Ethnicity and Screening for Sickle Cell/Thalassaemia. Oxford: Elsevier Churchill, 2005

21 Tapper M: In the blood. Philadelphia: University of Pennsylvania Press, 1999.

22 Jans SM, van El CG, Houwaart ES et al: A case study of haemoglobinopathy screening in the Netherlands: witnessing the past, lessons for the future. Ethn Health 2011; e-pub ahead of print 8 August 2011.

23 Weinreich SS, de Lange-de Klerk ES, Rijmen F et al: Raising awareness of carrier testing for hereditary haemoglobinopathies in high-risk ethnic groups in the Netherlands: a pilot study among the general public and primary care providers. BMC Public Health 2009; 9: 338.

24 Ajzen I: The theory of planned behaviour. Organ Behav Hum 1991; 50: 179-211.

25 Tsianakas V, Calnan M, Atkin K, Dormandy E, Marteau TM: Offering antenatal sickle cell and thalassaemia screening to pregnant women in primary care: a qualitative study of GPs' experiences. Br J Gen Pract 2010; 60: 822-828.

26 Vansenne F, de Borgie CA, Legdeur M, Spauwen MO, Peters M: Providing Genetic Risk Information to Parents of Newborns with Sickle Cell Trait: Role of the General Practitioner in Neonatal Screening. Genet Test Mol Biomarkers 2011; 15: 671-675.

27 Houwink EJ, van Luijk SJ, Henneman L, van d V, Jan DG, Cornel MC.: Genetic educational needs and the role of genetics in primary care: a focus group study with multiple perspectives. BMC Fam Pract 2011; 12: 5 .

28 van Hellemondt RE, Hendriks AC, Breuning MH: Regulating the use of genetic tests: Is Duch law an example for other countries with regard to DTC genetic testing? Amsterdam Law Forum 2011. Available from: http://ojs.ubvu.vu.nl/alf/article/view/ 194/368 (accessed on December 2011).

29 National Institute for Public Health and the Environment: Dutch National Atlas of Public health 2011. Available from: www.zorgatlas.nl (accessed on 16 August 2011).

30 The Netherlands Perinatal Registry: Perinatal Care in The Netherlands 2008 Utrecht, PRN-Foundation, 2011.

31 Poppelaars FA, Ader HJ, Cornel MC. et al: Attitudes of potential providers towards preconceptional cystic fibrosis carrier screening. J Genet Couns 2004; 13: 31-44.

32 Achterbergh R, Lakeman P, Stemerding D, Moors EH, Cornel MC: Implementation of preconceptional carrier screening for cystic fibrosis and haemoglobinopathies: a sociotechnical analysis. Health Policy 2007; 83: 277-286.

33 National Institute for Public Health and the Environment: Pre- and Neonatal Screening in The Netherlands 2011. Available from: www.rivm.nl/pns en (accessed on 16 August 2011).

34 Morgan MA, Driscoll DA, Mennuti MT, Schulkin J: Practice patterns of obstetriciangynecologists regarding preconception and prenatal screening for cystic fibrosis. Genet Med 2004; 6: 450-455.

35 Committee on Genetics ACOG. Update on carrier screening for cystic fibrosis committee opinion. no 486. Obstet Gynecol 2011; 117: 1028-1031.

36 National Institute for Public Health and the Environment: Bloodtests for Pregnant Women 2011. Available from: www.rivm.nl/pns_en/bloodtest (accessed on 16 August 2011).

37 Dormandy E, Michie S, Hooper R, Marteau TM: Low uptake of prenatal screening for Down syndrome in minority ethnic groups and socially deprived groups: a reflection of women's attitudes or a failure to facilitate informed choices? Int J Epidemiol 2005; 34: 346-352.

38 Lakeman P, Plass AM, Henneman L et al: Three-month follow-up of western and non-western participants in a study on preconceptional ancestry-based carrier couple screening for cystic fibrosis and hemoglobinopathies in the Netherlands. Genet Med 2008; 10: 820-830.

39 Tsianakas V, Atkin K, Calnan MW, Dormandy E, Marteau TM: Offering antenatal sickle cell and thalassaemia screening to pregnant women in primary care: a qualitative study of women's experiences and expectations of participation. Health Expect 2011; e-pub ahead of print 3 March 2011. 
40 Pal van der S, Kesteren van N, Dommelen van P, Detmar S: Willingness to Participate in Carrier Screening for Haemoglobinopathies Amongst High Risk Groups, Report no.: 09.049. Leiden, TNO KvL 2009.

41 Darr AR: Ethnic diversity and genetics: implications for families and service providers in the UK; in Broertjes JJS, Henneman L, Beemer FA (eds): Community Genetics. Past and Future. Utrecht: Department of Biological Education, 2002.

42 Wailoo K, Pemberton S: The Troubled Dream of Genetic Medicine. Baltimore: The John Hopkins University Press, 2006.

43 Wilson JMG Jungner.: Principles and Practice of Screening for Disease. Public Health Papers no. 34. Geneva: World health Organisation, 1968.
44 Lakeman P, Henneman L, Bezemer PD, Cornel MC, ten Kate LP: Developing and optimizing a decisional instrument using self-reported ancestry for carrier screening in a multi-ethnic society. Genet Med 2006; 8: 502-509.

\section{(c)}

This work is licensed under the Creative Commons



Unported License. To view a copy of this license, visit http:// creativecommons.org/licenses/by-nc-nd/3.0/ 